\title{
Evaluation of Biomarkers of Oxidative Stress in Attention-Deficit/ Hyperactivity Disorder (ADHD)
}

\author{
Verlaet Annelies, Robberecht Harry*, Weyand Ines, Breynaert Annelies, De Bruyne Tess and Hermans Nina \\ NatuRA (Natural Products and Food Research and Analysis), Laboratory of General and Functional Foods, Department of Pharmaceutical Sciences, University of \\ Antwerp, Belgium
}

\begin{abstract}
Biomarkers of oxidative stress and ADHD in children and adolescents are critically reviewed. They are divided in two groups: biomarkers of oxidative stress (general, proteins, including enzymes and non-protein biomarkers) and biomarkers of specific oxidative damage. Observed associations between concentration levels and ADHD symptoms are nearly always contradictory, which is partly due to aetiological a phenotypic complexity of the disorder. Some trends could be observed: lower ferritin and zinc levels, lower total antioxidant status (TAS), higher total oxidant stress (TOS) and higher oxidative stress index (OSI) are associated with ADHD. Even when there is a correlation most authors claim that this relationship is not causative, as illustrated by placebo-controlled trials reporting conflicting evidence on efficacy of supplementation. Well-defined studies could shed more light on their significance in this disorder by observing changes in concentration levels of the various biomarkers and ADHD symptoms before and after treatment with therapeutics.
\end{abstract}

\section{Keywords: ADHD; Biomarkers; Oxidative stress}

Abbreviations: 4-HNE: 4-Hydroxy-2-Nonenal, 8-ISO: 8-Isoprostane, 8-OHdG: 8-Hydroxy 2'-Deoxyguanosine, 8-OHG: 8-Hydroxy Guanosine, ADD: Attention-Deficit Disorder, ADHD: Attention Deficit/Hyperactivity Disorder, ALA: Alpha Linolenic Acid, AOPP: Advanced Oxidation Protein Products, APA: American Psychiatric Association, ARES: Arylesterase, CAT: Catalase, CNS: Central Nervous System, DISC1: Dismocollin-1, GR: Glutathione Reductase, GSH: Reduced Glutathione, GSSG: Oxidized Glutathione, GSH-Px: Glutathione Peroxidase, GST: Glutathione-S-Transferase, MDA: Malondialdehyde, MetS: Metabolic Syndrome, ORAC: Oxygen Radical Absorbance Capacity, OSI: Oxidative Stress Index, PON1: Paraoxonase 1, SPON: Stimulated PON, SOD: Superoxide Dismutase, TAC: Total Antioxidant Capacity, TAS: Total Antioxidant Status, TBARS: Thiobarbituric Acid Reacting Substances, TOS: Total Oxidant Status, XO: Xanthine Oxidase

\section{Introduction}

Attention-deficit/hyperactivity disorder (ADHD) is diagnosed on the basis of persistent and developmentally inappropriate levels of over activity, inattention and impulsivity [1]. ADHD is relatively common, affecting an estimated 5\% to $12 \%$ of school-aged children, depending on definition and study [2]. The aetiology and pathology of this disorder is not completely understood, although genetic $[3,4]$, interaction of genes and nutrition [5], epigenetic [6-8] and environmental factors, together with stress are mentioned [9]. Nutritional and dietary influences are reviewed $[10,11]$, while restriction and elimination diets have been tried in ADHD treatment [12,13]. Supplements [14] and complementary medicines (herbal and nutritional products) [15] have been systematically reviewed. Numerous medical potential causes have been linked to ADHD in children: oxidative stress [16,17], metal toxicity $[18,19]$, decreased methylation [20], mitochondrial dysfunction [21] and cerebral hypoperfusion [22]. An etiologic classification of attention-deficit/hyperactivity disorder has been reviewed [23,24]. For this review, a literature search was performed on biomarkers of oxidative stress and ADHD in children and adolescents. Although attention deficit disorder (ADD) is part of the ADHD spectrum, the search was limited to publications in which ADHD is explicitly mentioned.

\section{Literature Review}

A biomarker can be defined as "a characteristic that is objectively measured and evaluated as an indicator of biological and pathogenic processes or pharmacological responses to a therapeutic intervention" [25]. Biomarkers do not need to be exclusively linked to a particular disorder. For cancer (tumor markers) [26,27], vascular diseases [28], MetS [29], as well as many CNS disorders [30], including ADHD [31], various markers have been discussed. Oxidative stress represents a common etiological factor of diverse clinical conditions MetS [29,32], vascular diseases [28], hypertension [32], diabetes type 2 [32], as well as many CNS disorders [33], including ADHD [34] are mentioned in the literature. Therefore oxidative stress biomarkers can be related to various diseases. Sometimes genetic [3] and epigenetic markers [35] can be included in the broad group of "biomarkers".

Thome and co-workers [31] claimed that there are a lot of problems in developing ADHD biomarkers. Bradstreet and coworkers [36] reviewed biomarker-guided interventions in ADHD. They classified them as markers of 1) Oxidative stress; 2) Methylation and transsulfuration; 3) Immune dysregulation; 4) Mitochondrial dysfunction; 5) Heavy metal exposure, and 6) Cerebral dysfunction.

Scassellati et al. [37] reviewed biomarkers on this syndrome and classified them in groups, coming from: the monoaminergic neurotransmission systems, their enzymes and the metabolites; environmental risk factors (heavy metals); the hypothalamus-pituitaryadrenal axis pathway. Their observation that the concentration of brain-

*Corresponding author: Robberecht Harry, NatuRA (Natural Products and Food Research and Analysis), Laboratory of General and Functional Foods, Department of Pharmaceutical Sciences, University of Antwerp, Universiteitsplein 1, B-2610, Wilrijk, Belgium, Tel: +32 326541 11; E-mail: labrom@uantwerpen.be

Received April 18, 2018; Accepted May 05, 2018; Published May 15, 2018

Citation: Annelies V, Harry R, Ines W, Annelies B, Tess DB, et al. (2018) Evaluation of Biomarkers of Oxidative Stress in Attention-Deficit/Hyperactivity Disorder (ADHD). J Mol Biomark Diagn 9: 390. doi: 10.4172/2155-9929.1000390

Copyright: (c) 2018 Annelies V, et al. This is an open-access article distributed under the terms of the Creative Commons Attribution License, which permits unrestricted use, distribution, and reproduction in any medium, provided the original author and source are credited. 
derived neurotrophic factor (BDNF) in ADHD was not different from those of controls [38], was contradictory to the increased levels of this factor in another study [39]. This illustrates that a lot of contradictory results are found in literature. In addition, the question remains whether the change in a biomarker is a cause or a response to the disease. More recently Bonvincini et al. [40] discussed common and specific genes and peripheral biomarkers in ADHD. Described genes belong primarily to the dopaminergic and neurodevelopmental systems. The authors reviewed oxidative stress markers (MDA, SOD, PON1, ARES, TAS, TOS and OSI) and second level markers (DISC1, microRNA and adiponectin). Additionally indicators of disturbed immunity are studied [41], including neopterin [42] and adenosine deaminase [43]. All this illustrates that ADHD is a complex, multifactorial disorder that arises from many risk factors, none of which are necessary or sufficient to cause the disorder.

Oxidative/nitrosative stress is defined as an imbalance between reactive oxygen/nitrogen species (ROS/RNS) and the organism's capacity to counteract their action [44]. Oxidative stress emerges from an enhanced ROS/RNS generation or from a decay of the antioxidant protective ability. This result in a reduced capacity of endogenous and exogenous systems to fight against the oxidative attack directed towards target biomolecules [45]. This imbalance could lead to detrimental effects. Because markers for oxidative stress are related to various diseases, they cannot be used as a specific diagnostic requirement of any exclusive disorder. It is medically reasonable to assume that the decrease of oxidative stress would be associated with amelioration of some features of these disorders, or at least prevent or slow their progression. In this review we have limited ourselves to markers of oxidative stress in ADHD of children and adolescents, which means that papers on the adult form of this disease are excluded [46-50].

The adult form can have other characteristics with related other findings on biomarkers. To illustrate this: malondialdehyde levels in adult patients were higher compared to controls [46,48], whereas for children lower levels were found in patients [51,52]. Also other factors (work, environmental pollution, alcohol abuse, smoking attitude) can result in enhanced oxidative stress. Division of markers into groups has limitations, since some overlap cannot be excluded and the risks of being subject to discussion always remain. Although the use of biomarkers in the diagnosis of ADHD appeared promising [53], only one review on markers of oxidative stress has been found [34]. Faraone and co-workers [53] concluded from their meta-analysis on oxidative stress and antioxidant status in medication naïve patients with ADHD that they have normal levels of antioxidant production. The response to oxidative stress however turned out to be insufficient, leading to oxidative damage of biomolecules such as cytoskeletal proteins, membrane lipids, and DNA. We have screened the literature using the terms "ADHD", "biomarkers of antioxidant status", "biomarkers of oxidative stress" and the various individual markers. References from 2000 onwards are used or some important previous references cited therein. We have tried to divide the biomarkers into two groups: biomarkers of oxidative stress on one hand and markers of specific oxidative damage on the other. The first group includes biomarkers of the oxidative balance, non-protein and protein biomarkers of oxidative stress. In the latter group the protein biomarkers can either be enzymes or have a non-enzymatic function. In the second group damage to biochemical molecules (DNA, RNA, proteins and lipids) are reviewed. Mostly plasma or serum is the monitored medium, but saliva, urine, as well as exhaled breath are included.

\section{Discussion}

\section{Biomarkers of oxidative stress}

Reactive oxygen (ROS) and reactive nitrogen species (RNS), such as superoxide, nitric oxide, peroxynitrite, and hydrogen peroxide are unstable molecules that can react with cells/molecules in the body. They are generated during normal cellular metabolism, mainly formed within the mitochondria. ROS and RNS can also be generated from ultraviolet light irradiation, environmental pollutants, and by neutrophils, eosinophils, and macrophages during inflammation via their influence on proteins, fatty acids and DNA, ROS and RNS have numerous essential physiological roles involved in the regulation of cellular function $[54,55]$.

There is a balance between oxidative and anti-oxidative systems. Antioxidants remove ROS and RNS by scavenging radicals and decreasing their production. Examples of scavenger antioxidants are coenzyme Q10 (CoQ10), Vitamin C and E, and glutathione. ROS may also be neutralized by different antioxidant enzymes such as superoxide dismutase (SOD), glutathione peroxidase (GSH-Px), and catalase (CAT). Some proteins including acute phase proteins such as albumin, transferrin, haptoglobin, and ceruloplasmin also function as antioxidants by binding ROS and RNS [56]. Anti-oxidants sometimes are divided into two groups: the endogenous antioxidants (SOD, CAT, GSH-Px, thiol-groups in proteins, metal-binding proteins, uric acid, bilirubin, reduced coenzyme Q, lipoid acid, endogenous Se) and exogenous ones (vitamin E, vitamin $\mathrm{C}$, carotenoids, phenolic antioxidants, resveratrol, cinnamic acid, lecithins, acetylcysteine and exogenous $\mathrm{Se}$ ). Also this division could be discussed. Considering the trace element Se, what is the most effective and should be monitored best: the endogenous or exogenous Se? Moreover, both are related to each other.

\section{Biomarkers of oxidative balance (TAS, TOS, OSI)}

Total oxidant status (TOS) and total antioxidant status (TAS) are valid and reliable methods to identify changes in oxidant and antioxidant parameters that may contribute to the aetiopathogenesis of a disease. The oxidative stress index (OSI, the ratio of TOS/TAS) reveals how much a current situation deviates from normal homeostasis [57].

Sometimes the expression total antioxidant capacity (TAC) is used, but this refers to an estimation of dietary total antioxidant capacity in which flavonoids and vitamin $\mathrm{C}$ and $\mathrm{E}$ are major contributors, via fruits and vegetables [58]. There are databases including the content of more than 40 individual antioxidants and the TAC per food item. These are: retinol, vitamin C, 4 forms of vitamin $\mathrm{E}$ ( $\alpha$-tocopherol, $\beta$-tocopherol, $\gamma$-tocopherol and $\delta$-tocopherol), 6 forms of carotenoids ( $\alpha$-carotene, $\beta$-carotene, $\beta$-cryptoxanthin, lutein, lycopene, and zeaxanthin), 7 flavonoid subclasses (flavonols, flavones, flavanones, flavan-3-ols, anthocyanins, isoflavones, proanthocyanidins) and different others. TAC is measured by using the oxygen radical absorbance method (ORAC) [59]. Table 1 summarizes findings on the three most measured parameters (TAS, TOS and OSI). Findings are quite consistent, only the observed higher TAS values by Celik et al. [60] are unexpected.

\section{Non-protein biomarkers of oxidative stress}

a) NO: Higher NO levels were observed in plasma of patients compared to controls $[61,62]$. However, contradictory observations were found as also lower values [63] or no significant differences [64] were observed.

b) GSH/GSSG: Measuring total glutathione (Reduced: GSH, 


\begin{tabular}{|c|c|c|c|}
\hline Parameters & Medium & $\begin{array}{l}\text { Difference compared } \\
\text { to controls }\end{array}$ & References \\
\hline \multirow{7}{*}{ TAS } & Serum & $\downarrow$ & Sezen et al. [140] \\
\hline & Plasma & $\downarrow$ & Chovanova et al. [17] \\
\hline & Plasma & $\downarrow$ & Dvorakova et al. [20] \\
\hline & Plasma & $\downarrow$ & Ruchi et al. [146] \\
\hline & Plasma & $\downarrow$ & Ceylan et al. [43] \\
\hline & Plasma & $\downarrow$ & Kul et al. [172] \\
\hline & Plasma & $\uparrow$ & Celik et al. [60] \\
\hline \multirow{3}{*}{ TOS } & Serum & $\uparrow$ & Sezen et al. [140] \\
\hline & Plasma & $\uparrow$ & Kul et al. [172] \\
\hline & Plasma & $\uparrow$ & Guney et al. [71] \\
\hline \multirow{3}{*}{ OSI } & Serum & $\uparrow$ & Sezen et al. [140] \\
\hline & Plasma & $\uparrow$ & Kul et al. [172] \\
\hline & Plasma & $\uparrow$ & Guney et al. [71] \\
\hline
\end{tabular}

Note: TAS: Total Antioxidant Status, TOS: Total Oxidant Status, OSI: Oxidative Stress Index

Table 1: Oxidative/anti-oxidative balance in paediatric ADHD

along with oxidized: GSSG) and/or GSH will help to determine a patient's oxidation status. Our research group found statistically ( $\mathrm{p} \leq$ 0.001) higher GSH-values in ADHD children compared to controls. A standardized polyphenolic extract from pine bark, Pycnogenol acts as a powerful antioxidant [65]. One month administration of this extract $(1 \mathrm{mg} / \mathrm{kg}$ body weight/day) caused a significant decrease in GSSG and increase in GSH levels, as well as improvement of GSH/GSSG ratio in comparison to a group taking placebo $[20,66]$.

c) Plasma thiol-levels: Thiols have an important role in coordinating the antioxidant defence system. They can undergo oxidation reactions mediated by ROS and other free radicals forming disulphide bonds [67]. These disulphide bonds are eventually reduced to thiol groups by antioxidants. In this way the thiol/disulphide homeostasis is maintained [68].

Total thiol levels in serum were significantly higher whereas the disulphide/thiol ratios were lower in children with ADHD compared to controls. Disulphide levels in males with ADHD were significantly higher than those of females. This can be due to the fact that boys may have another type of ADHD. The study suggests that thiol/disulphide homeostasis is abnormal in children with ADHD and can be used as a novel oxidative stress marker in these children [69]. Enhanced levels of protein thiols in saliva were also found in paediatric ADHD compared to the controls [70]. Oztop et al. [52] however did not find a significant difference in thiol levels in ADHD children compared to controls, while Guney et al. [71] proved to find lower plasma thiol levels in ADHD children. This could be considered as a consequence of the elevated oxidative stress. On the other side, higher thiol levels can be considered as a crucial antioxidant reaction in children with ADHD and might be interpreted as a consequent increase assisting in the activation of metabolism and to reduce the oxidative stress [69]. Selek et al. [47] indeed interpreted this finding as a rebound effect.

\section{Anti-oxidative vitamins (A, C, D and E)}

a) Vitamin C: Literature data on vitamin $\mathrm{C}$ and $\mathrm{ADHD}$ are scarce. Supplementation of $25 \mathrm{mg}$ vitamin C, together with $200 \mathrm{mg}$ alpha linolenic acid (ALA), twice a day and for 3 months, improved the outcome of ADHD [72].

b) Vitamin D: Vitamin D is involved in the control of serotonin synthesis and action [73]. An inverse association between umbilical cord $25-\mathrm{OH}$ vitamin $\mathrm{D}$ [74] or maternally circulating vitamin D levels in pregnancy [75] and ADHD in their toddlers was found, suggesting a protective effect of prenatal vitamin D. Another study found no association between maternal vitamin D status and ADHD in the offspring [76]. Also Gustafsson et al. [77] found no difference in intrauterine vitamin D levels between children later developing ADHD and matched control children. But the authors agree that the statistical power of their study was too weak to detect an association. Lower levels of vitamin D have been found in ADHD children [78-87]. These lower levels of the 25-OH vitamin D in children with ADHD suggest that vitamin $\mathrm{D}$ level might be related to ADHD, but is not necessarily a cause [88]. Vitamin D supplementation was suggested as adjunctive therapy to methylphenidate for improving ADHD symptoms [89].

c) Vitamin E: Increased concentrations of $\gamma$-tocopherol were found in ADHD patients, together with reduced lipid peroxidation [51].

d) Vitamin A: Vitamin A has shown some antioxidant and neuroprotective effect [90], however this vitamin does not reveal abnormal concentrations in paediatric ADHD patients [51].

\section{Co-factors (Fe, Zn, Cu, Mg, Se)}

Iron $(\mathrm{Fe})$ and zinc $(\mathrm{Zn})$ are essential cofactors in the production of dopamine and norepinephrine and both play a pivotal role in oxidant/ antioxidant mechanisms. Dysregulation of the $\mathrm{Fe}$ and $\mathrm{Zn}$ status could lead to increased susceptibility to oxidative damage, which is a reasonable hypothesis in the pathophysiology of ADHD.

a) Iron: Iron deficiency has been suggested as possibly contributing to the aetiology of ADHD in children [79,91] but this is also questioned $[92,93]$. Nevertheless, it is hypothesized that the treatment of iron deficiency or suboptimal levels might lead both to improvement of the severity of ADHD symptoms and to a decrease of the risk of cardiovascular events during treatment with ADHD drugs [94]. A systematic review of the literature intended to offer empirical evidence for a link between iron and ADHD [95,96]. Table 2 summarizes literature data on iron status in ADHD. Fe status was generally evaluated through serum ferritin levels (iron stores), although also serum iron levels or transferrin $[97,98]$ were mentioned. Nearly all data indicate lower ferritin levels in ADHD patients. Only one publication claimed to find higher levels [99]. The discussion remains whether iron deficiency is causative of ADHD [92,93], or a consequence. It is e.g. possible that low iron stores result from a decreased appetite as a consequence of ADHD medication. It is also possible that patients with ADHD have a decreased ability to sit still during the meals and therefore have decreased nutritional intake of iron [92]. This can also be the case for other nutrients.

Patients receiving an iron supplement $(5 \mathrm{mg} / \mathrm{kg} / \mathrm{day}$ for 30 days) showed a significant increase in serum ferritin levels and a significant decrease of the parents' Connors Rating Scale scores [100]. A supplementation of $80 \mathrm{mg} /$ day also improved ADHD symptoms $[101,102]$. After a systematic review there is a need for more evidence for the effect of iron supplementation (as well as for magnesium and zinc) in the treatment of ADHD among children [103]. Indeed, iron overload (measured by serum ferritin levels) can become a risk factor for oxidative damage and in this way a marker of oxidative stress [29].

b) Zinc: Zinc is a cofactor for enzymes involved in cell membrane stabilization and in the metabolism of neurotransmitters, melatonin [104], and prostaglandins. Zn also has indirect effects on dopamine metabolism (the dopamine transporter is regulated by $\mathrm{Zn}^{2+}$ [105] and has antioxidant functions [106]. Case-control trials in several geographical areas have demonstrated lower zinc levels in children 
Citation: Annelies V, Harry R, Ines W, Annelies B, Tess DB, et al. (2018) Evaluation of Biomarkers of Oxidative Stress in Attention-Deficit/Hyperactivity Disorder (ADHD). J Mol Biomark Diagn 9: 390. doi: 10.4172/2155-9929.1000390

Page 4 of 10

\begin{tabular}{|c|c|c|c|}
\hline Parameters & Effect observed & Remarks & References \\
\hline \multirow{25}{*}{ Ferritin } & $=$ & No Relationship With Symptoms & Menegassi et al. [174] \\
\hline & $=$ & - & Romanos et al. [183] \\
\hline & $=$ & - & Donfrancesco et al. [168] \\
\hline & $\uparrow$ & - & Abu-Khadra et al. [163] \\
\hline & $\downarrow$ & - & Antalis et al. [99] \\
\hline & $\downarrow$ & Higher Connors Rating Scale Scores & Sever et al. [100] \\
\hline & $\downarrow$ & Higher Conners Rating Scale Scores & Juneja et al. [169] \\
\hline & $\downarrow$ & Contribution to ADHD & Konofal et al. [101] \\
\hline & $\downarrow$ & No Causative Role & Millichap et al. [175] \\
\hline & $\downarrow$ & Increased Risk of Restless Legs & Oner et al. [176] \\
\hline & $\downarrow$ & - & Konofal et al. [171] \\
\hline & $\downarrow$ & Related With Behavioral But Not With Cognitive Measures & Oner et al. [177] \\
\hline & $\downarrow$ & Higher Behavioral Problems & Oner and Oner [178] \\
\hline & $\downarrow$ & Related to Sleep Disturbances & Cortese et al. [166] \\
\hline & $\downarrow$ & Higher Hyperactivity Symptoms & Oner et al. [111] \\
\hline & $\downarrow$ & - & Mahmoud et al. [112] \\
\hline & $\downarrow$ & Related to ADHD & Calarge et al. [95] \\
\hline & $\downarrow$ & - & Lahat et al. [91] \\
\hline & $\downarrow$ & Hyperactivity Reported by Parents & Oner et al. [179] \\
\hline & $\downarrow$ & Compared to Healthy As Well As Psychiatric Controls & Cortese et al. [96] \\
\hline & $\downarrow$ & Not Causative Role & Villagomez and Ramtekkar, [80] \\
\hline & $\downarrow$ & Link with ADHD and Obesity & Cortese and Agriman [165] \\
\hline & $\downarrow$ & Associated with ADHD & Bener et al. [79] \\
\hline & $\downarrow$ & Correlated with Hyperactivity Scores & Percinel et al. [182] \\
\hline & $\downarrow$ & Systematic Review & Wang et al. [185] \\
\hline Transferrin & $\downarrow$ & Relationship with ADHD Symptoms & Kwon et al. [97] \\
\hline Corum 50 & $=$ & - & Wang et al. [185] \\
\hline Setumitre & $\downarrow$ & - & Bener et al. [79] \\
\hline
\end{tabular}

Table 2: Iron status in paediatric ADHD.

with ADHD compared to healthy controls [80,107-114]. Only one publication mentions higher hair zinc levels and ADHD [115]. However, this article would be more informative if this trend could be related to changed zinc levels in serum, since zinc in hair is a long-term parameter. Several meta-analyses also suggest a significant association between low zinc levels and a diagnosis of ADHD [37,106,116-118]. Neither of these observations however does prove that zinc deficiency causes ADHD nor that this disorder should be treated with zinc [106]. Randomized, placebo-controlled trials of zinc supplementation either as an adjuvant to psychostimulant treatment or as monotherapy have provided conflicting evidence of efficacy [10,28,117,119-124]. Evidence is insufficient to recommend zinc supplementation in areas where zinc deficiencies are rare. Also the dosing and the form of zinc supplementation varied widely between the trials, so an optimal dosing strategy is not apparent [14].

c) Copper: Only one publication on blood level of this trace element and ADHD could be traced [114]. Copper levels in ADHD children were higher than those in the control group, however, not significantly $(\mathrm{p}>0.05)$.

d) Magnesium: Magnesium $\left(\mathrm{Mg}^{2+}\right)$ is an abundant cation in the intracellular compartment of humans and of great physiological importance [125]. Literature data on $\mathrm{Mg}$ levels in blood in ADHD patients revealed contradictory results. Higher [126], as well as lower levels $[80,99,112,127]$ were found. Magnesium levels in saliva were significantly decreased in ADHD patients [70], as well as in hair [127]. Supplementation studies with $\mathrm{Mg}$, mostly in combinations with $n-3 / n-6$ fatty acids and zinc, resulted in a considerable reduction in symptoms [120].

e) Selenium: Selenium (Se) acts as a cofactor in the antioxidant enzyme glutathione peroxidase (GSH-Px) [128]. No significant differences in Se levels between controls and ADHD children were found [114]. However, low intake of Se was observed in ADHD groups compared to controls [129]. The restlessness of the children could be responsible for reduced meal times with resulting lower intake of various elements. An unexpected relatively high umbilical cord Se level was observed in children afterwards manifesting ADHD [130]. This observation should be interpreted with caution.

f) Uric acid: Uric acid is a strong reducing agent and hence a potent antioxidant. However it remains contradictory whether it induces or lowers oxidative stress, as acute elevation appears a protective factor, while chronic elevation is a risk for disease [131]. No publications on uric acid concentrations in ADHD children could be found.

g) Bilirubin: Bilirubin is an active scavenger of peroxyl radicals and lowers the mutagenic activity of oxidative species, polycyclic 
aromatic hydrocarbons and heterocyclic amines [132,133]. However its role in development of ADHD is quite confusing [134]. Contrary to the scavenging character of the molecule, neonatal jaundice seems to increase the risk of ADHD [135], especially for those requiring phototherapy and longer treatment. Hyperbilirubineamia is associated with childhood symptoms of hyperactivity [136] possibly when serum bilirubin concentrations exceed protein-binding capacities, bilirubin crystals aggregate and precipitate in neurons [135], and causing behavioural problems. For the ADD form in the ADHD spectrum no association was found [137], contrary to results for the same type of disorder in Canada [138].

\section{Proteins with influence on oxidative stress}

\section{Enzymes (PON1, GSH-Px, ARES, SOD, GST, GR, CAT, XO):}

a) Paraoxonase 1: Paraoxonase 1 (PON1), which has antioxidant properties, is a multifunctional enzyme with paraoxonase (PON), diazoxonase and arylesterase (ARES) activities [139].

Lower PON activities were found in children with ADHD $[43,140]$. In contrast to these findings, Oztop et al. [52] did not report a significant association between ADHD and PON1. Guney et al. [71] did not observe lower levels of PON1, but after a short term follow up study post-treatment enzyme activity became significantly higher for PON1, as well as for salt- and activity-stimulated paraoxonase (SPON).

b) Glutathione peroxidase: The antioxidant activity of glutathione peroxidase (GSH-Px) was found to be significantly lower in ADHD patients than in controls $[62,141]$. Since selenium is a cofactor of this enzyme it should be suspected that this trace element also is lower in ADHD patients. However, this was not proven to occur [114].

c) Arylesterase: Some authors found a decreased activity of arylesterase (ARES) in ADHD children [140], while others did not [71].

d) Superoxide dismutase: Russo [142] claimed that the activity of this $\mathrm{Cu} / \mathrm{Zn}$ dependent SOD is lower in ADHD children, particularly in those patients with high serum copper. Similar observations were published by Adham et al. [141]. No explanation therefore was given. After 8 weeks n-3 supplementation, Hariri et al. [143] found a significant increase in SOD activity in ADHD children. Another group did not find differences in SOD activity between patients and controls [62].

e) Glutathione transferase: Glutathione S-transferase (GST) is an antioxidant enzyme which plays a key role in cellular detoxification. Also here, contradictory findings were published on enzyme activity in plasma of ADHD children. Higher [60], as well as lower activity, compared to controls, were claimed [43,141]. No significant association between specific gene polymorphisms for this enzyme and the incidence of ADHD was observed [144].

f) Glutathione reductase: Glutathione reductase (GR) plays a major role in antioxidant defence as impaired GSH regeneration enhances oxidative damage [145]. After 8 weeks of $n-3$ fatty acid supplementation, Hariri et al. [143] found a significant increase in GR activity in plasma of ADHD children.

g) Catalase: The activity of this antioxidant enzyme was not significantly different in ADHD patients and controls [60,62]. Hariri et al. [143] supplemented n-3 fatty acids for 8 weeks to ADHD patients and found no difference compared to the beginning levels of CAT. Lower catalase activity in serum [141] and in saliva of an ADHD group was observed compared to the controls [146]. h) Xanthine oxidase: $\mathrm{XO}$ activity was significantly higher in serum of ADHD patients compared to controls [43]

i) Nitric oxide synthase: An enhanced nitric oxide synthase (NOS) activity was observed [43]

j) Non-enzymatic proteins: Transferrin and ferritin, but also lactoferrin, ceruloplasmin and even albumin have been confirmed as non-enzymatic antioxidants. They probably act by sequestrating transition metal ions responsible for the generation of the reactive oxygen radical species [147]. However no literature data on serum levels of lactoferrin, ceruloplasmin and albumin in ADHD could be traced. Ceruloplasmin levels in saliva of ADHD patients were not different from those of controls [70].

\section{Biomarkers of specific oxidative damage}

a) Proteins: Advanced oxidation protein products (AOPP) can be used as a marker of oxidative damage to proteins. Oztop et al. [52] did not find a significant difference between the concentrations of AOPP in children with ADHD versus healthy controls. Acrolein-lysine adduct is considered as a marker of lipid peroxidation and oxidative protein damage $[148,149]$. Urinary levels of this adduct appeared higher in ADHD children than control subjects [150]. Levels of butane, a marker of protein oxidation were unaltered in breath of ADHD patients, compared to controls [151]. 3-nitrotyrosine is an oxidative marker of protein damage as associated with bipolar disease [152]. However no publications could be traced linking the concentration with ADHD.

b) DNA: Measuring urinary 8-hydroxy-2'-deoxyguanosine (8OHdG) has become the most widely used technique to assess oxidative DNA-damage. There are several reasons why it is regarded by many laboratories as a valid biomarker of oxidative DNA damage [17,51]. 8-OHdG is formed in DNA by reactive species and its importance is reflected by its mutagenicity by inducing GC: TA transition, as well as by the presence of DNA repair mechanisms to remove 8-OHdG from DNA [153]. Quite contradictory Oztop et al. [52] found lower values of this biomarker in ADHD children.

c) RNA: A marker for oxidative damage to RNA is 8-oxoguanosine. Chovanova et al. [17] found that Pycnogenol $^{\circledR}$ administration reduced oxidative damage in RNA as measured by reduced levels of 8oxoG 4 weeks after treatment.

\section{Fatty acids}

a) MDA: Malondialdehyde (MDA) is the breakdown product of the major chain reactions occurring after oxidation of polyunsaturated fatty acids and thus serves as a marker of oxidative stress [154,155]. Studies on levels of this biomarker in ADHD patients revealed contradictory findings: lower [51,52] as well as higher levels have been reported [62].

b) TBARS: The most widely used index of lipid peroxidation is the measurement of thiobarbituric acid reactive substances (TBARS), which includes MDA. However, the use of the TBARS test to assess oxidative stress status in human fluids is problematic for several reasons: a) aldehydes other than MDA may react with TBA; b) decomposition of lipid peroxides during the test itself may mask the actual MDA content before testing; $c$ ) the presence or absence of metal ions or other undefined radicals affects the rate of this decomposition, and d) most TBA-reactive material, including MDA, in human body fluids is not a specific product of lipid peroxidation and may produce false-positive results [156]. Other pitfalls in the measurement of TBARS are summarized by Hermans et al. [153]. Flax oil supplementation corresponding to $200 \mathrm{mg}$ ALA content along with $25 \mathrm{mg}$ vitamin C 
twice a day for 3 months improves the outcome of ADHD, however resulted in higher post-supplementaion plasma TBARS levels [72].

c) 4-hydroxy-nonenal: Although 4-hydroxy-nonenal (4-HNE), a bioactive lipid peroxidation product [157], is claimed to be related to brain diseases [55], no studies were found, in which levels of 4-HNE were measured in ADHD patients.

d) Isoprostanes: Urinary concentration of isoprostanes is considered as a marker of lipid peroxidation [158]. However no publications on this marker and ADHD could be found.

e) Acrolein-lysine: Acrolein-lysine adduct is a marker of lipid peroxidation and oxidative protein damage $[148,149]$. It has been found to be elevated in neonates as a consequence of oxidative stress [159]. Urinary levels appeared to be higher in ADHD children than those of the control subjects [150].

f) Ethane: Breath ethane concentration is considered as a marker of systemic lipid peroxidation [160]. Its concentration significantly correlates with blood hydroperoxide concentrations and inversely correlated with that of vitamin E. Patients with ADHD had higher ethane levels in exhalant breath than healthy volunteers [151].

\section{Conclusion}

A problem in the development of oxidative stress biomarkers in ADHD is sample heterogeneity due to aetiological and phenotypic complexity and co-morbidities. Most likely, it is not feasible to identify one single, reliable, reproducible, non-invasive and easy to use biomarker with high sensitivity and specificity. The use of a combination of markers may help to reduce heterogeneity and to identify more homogeneous subtypes of ADHD. In addition, the determination of one or two markers of oxidative stress will not reflect the real redox status in an organism. The evaluation of total oxidative stress (TOS) and total anti-oxidant status (TAS) and their ratio as oxidative stress index OSI) could be more useful for identification of redox imbalance $[57,161,162]$. Due to the small number of studies and their variety, no definitive conclusions concerning involvement of oxidative stress in pathophysiology of ADHD can be drawn. The contradictory findings in literature may depend largely on the amount of diagnostic parameters and the treatment patients already received. Further on, the question arises whether a lower or higher level of a biomarker is causative for the disease or just a consequence. Moreover, oxidative stress can increase anti-oxidative response, further increasing the complexity of interpretation of oxidative stress related biomarkers. Hopefully, additionally well-defined studies could shed more light on changed levels of various biomarkers before and after treatment with therapeutics in ADHD [163-184].

\section{Acknowledgements}

This paper is dedicated to the memory of our colleague Sandra Apers ('19/08/1972-+05/02/2017).

\section{References}

1. American Psychiatric Association (APA) (2013) Diagnostic and statistical manual of mental disorders, 4th ed., Text Revision (DSM-V). American Psychiatric Association, Washington DC, USA

2. Scahill L, Schwab-Stone M (2000) Epidemiology of ADHD in school-age children. Child Adolesc Psychiatr Clin N Am 9: 541-555.

3. Drtilkova I, Sery O, Theiner P, Uhrova A, Zackova M, et al. (2008) Clinical and molecular-genetic markers of ADHD in children. Neuro Endocrinol Lett 29: 320327.

4. Akutagava-Martins GC, Rohde LA, Hutz MH (2016) Genetics of attentiondeficit/hyperactivity disorder: an update. Expert Rev Neurother 16: 145-156.
5. Field SS (2014) Interaction of genes and nutritional factors in the aetiology of autism and attention deficit/hyperactivity disorders: A case control study. Medical Hypotheses 82: 654-661.

6. Schuch V, Utsumi DA, Costa TV, Kulikowski LD, Muszkat M (2015) Attention deficit hyperactivity disorder in the light of the epigenetic paradigm. Front Psychiatry 6: 126.

7. Cecil CA, Walton E, Barker ED (2016) Prenatal diet and childhood ADHD exploring the potential role of IGF2 methylation. Epigenomics 8: 1573-1576.

8. Walton E, Pingault JB, Cecil CA, Gaunt TR, Relton CL, et al. (2017) Epigenetic profiling of ADHD symptoms trajectories: a prospective, methylome-wide study Mol Psychiatry 22: 250-256.

9. Verlaet A, Noriega D, Hermans N, Savelkoul H (2014) Nutrition, immunological mechanisms and dietary immunomodulation in ADHD. Eur Child Adolesc Psychiatr 23: 519-529.

10. Sinn N (2008) Nutritional and dietary influences on attention deficit hyperactivity disorder. Nutr Rev 66: 558-568

11. Millichap JG, Yee MM (2012) The diet factor in attention-deficit/hyperactivity disorder. Pediatrics 129: 330 .

12. Nigg JT, Holton K (2014) Restriction and elimination diets in ADHD treatment. Child Adolesc Psychiatric Clin N Am 23: 937-953.

13. Heilskov Rytter MJ, Andersen LB, Houmann T, Houmann T, Bilenberg N, et al. (2015) Diet in the treatment of ADHD in children - systematic review of literature. Nord J Psychiatry 69: 1-18.

14. Bloch MH, Mulqueen $\mathrm{J}$ (2014) Nutritional supplements for the treatment of attention-deficit hyperactivity disorder. Child Adolesc Psychiatr Clin N Am 23 883-897.

15. Sarris J, Kean J, Schweitzer I, Lake J (2011) Complementary medicines (herbal and nutritional products) in the treatment of attention deficit hyperactivity disorder (ADHD): A systematic review of evidence. Complem Therap Med 19: 216-227.

16. Ross M (2000) Could oxidative stress be a factor in neurodevelopmental disorders? Prostaglandins Leukotr Essential Fatty Acids 63: 61-63.

17. Chovanova Z, Muchova J, Sivonova M, Dvoráková M, Zitnanová I, et al. (2006) Effect of polyphenolic extract, Pycnogenol, on the level of 8-oxoguanine in children suffering from attention deficit/hyperactivity disorder. Free Radic Res 40: 1003-1010.

18. Tuthill RW (1996) Hair lead levels related to children's classroom attentiondeficit behaviour. Arch Environ Health 51: 214-220.

19. Braun JM, Kahn RS, Froelich T, Auinger P, Lanphear BP (2006) Exposures to environmental toxicants and attention deficit hyperactivity disorder in U.S. children. Environ Health Perspect 114: 1904-1909.

20. Dvorakova M, Sivonova M, Trebaticka J, Skodácek I, Waczuliková I, et al. (2006) The effect of polyphenolic extract from pine bark, Pycnogenol on the level of glutatione in children suffering from attention deficit hyperactivity disorder (ADHD). Redox Rep 11: 163-172.

21. Richardson AJ (2006) Omega-3 fatty acids in ADHD and related neurodevelopmental disorders. Int Rev Psychiatry 18: 155-172.

22. Amen D, Carmichael B (1997) High-resolution brain SPECT imaging in ADHD. Ann Clin Psychiatry 9: 81-86.

23. Millichap JG (2008) Etiologic classification of attention-deficit/hyperactivity disorder. Pediatr 121: e358.

24. Stevens LJ, Kuczek T, Burgess JR, Hurt E, Arnold LE (2011) Dietary sensitivities and ADHD symptoms: thirty-five years of research. Clin Pediatr 50: 279-293.

25. Chakravarty A (2005) Regulatory aspects in using surrogate markers in clinical trials. In: Burzykowski T, Molenberghs G, Buyse M, (eds) Statistics for Biology and Health. The evaluation of surrogate endpoints. New York, NY: Springer Science and Business Media, Inc. 2: 13-51.

26. Clinton T, Lotan Y (2017) Review of the clinical approaches to the use of urinebased tumor markers in bladder cancer. Rambam Maimonides Med J p: 8

27. Virgilio E, Proietti A, D'Urso R, Cardelli P, Giarnieri E, et al. (2017) Measuring intra-gastric tumor markers in gastric cancer patients: A systematic literature review on significance and reliability. Anticancer Res 37: 2817-2821.

28. Bruchfeld A, Carrero JJ, Qureshi AR, Lindholm B, Barany P, et al. (2009) 
Citation: Annelies V, Harry R, Ines W, Annelies B, Tess DB, et al. (2018) Evaluation of Biomarkers of Oxidative Stress in Attention-Deficit/Hyperactivity Disorder (ADHD). J Mol Biomark Diagn 9: 390. doi: 10.4172/2155-9929.1000390

Elevated serum macrophage migration inhibitory factor (MIF) concentrations in chronic kidney disease (CKD) are associated with markers of oxidative stress and endothelial activation. Mol Med 15: 70-75.

29. Robberecht H, Hermans N (2016) Biomarkers of metabolic syndrome: biochemical background and clinical significance. Metabol Syndr Related Disord 14: 47-93.

30. Michel TM, Pülschen D, Thome J (2012) The role of oxidative stress in depressive disorders. Curr Pharm Des 18: 5890-5899.

31. Thome J, Ehlis AC, Fallgatter AJ, Krauel K, Lange KW, et al. (2012) Biomarkers for attention-deficit/hyperactivity disorder (ADHD). A consensus report of the WFSBP task force on biological markers and the World Federation of ADHD. World J Biol Psychiatry 13: 379-400.

32. Roberts CK, Sindhu KK (2009) Oxidative stress and metabolic syndrome. Life Sci 84: 705-712.

33. Ng F, Berk M, Dean O, Bush Al (2008) Oxidative stress in psychiatric disorders: evidence base and therapeutic implications. Int J Neuropsychopharmacol 11 $851-876$

34. Joseph N, Zhang-James Y, Perl A, Faraone SV (2012) Oxidative stress and ADHD: A meta-analysis. J Atten Disord 20: 1-10.

35. Xu Y, Chen XT, Luo M, Tang Y, Zhang G, et al. (2015) Multiple epigenetic factors predict the attention deficit/hyperactivity disorder among the Chinese Han children. J Psychiatr Res 64: 40-50.

36. Bradstreet JJ, Smith S, Baral M, Rossignol DA (2010) Biomarker-guided interventions of clinically relevant conditions associated with autism spectrum disorders and attention deficit hyperactivity disorder. Altern Med Rev 15: 15-32.

37. Scassellati C, Bonvicini C, Faraone SV, Gennarelli M (2012) Biomarkers and attention-deficit/hyperactivity disorder: a systematic review and meta-analysis. J Am Acad Child Adolesc Psychiatry 51: 1003-1019.

38. Scassellati C, Zanardini R, Tiberti A, Pezzani M, Valenti V, et al. (2014) Serum brain-derived neurotrophic factor (BDNF) levels in attention deficit-hyperactivity disorder (ADHD). Eur Child Adolescent Psychiatry 23: 173-177.

39. Shim SH, Hwangbo Y, Kwon YJ, Jeong HY, Lee BH, et al. (2008) Increased levels of plasma brain-derived neurotrophic factor (BDNF) in children with attention deficit-hyperactivity disorder (ADHD). Prog Neuropsychopharmacol Biol Psychiatry 32: 1824-1828.

40. Bonvicini C, Faraone S, Scassellati C (2017) Common and specific genes and peripheral biomarkers in children and adults with attention-deficit/hyperactivity disorder. World J Biol Psychiatry 19: 80-100.

41. Verlaet AA, Ceulemans B, Verhelst $H$, West D, Bruyne T, et al. (2017) Effect of Pycnogenol ${ }^{R}$ on attention-deficit hyperactivity disorder (ADHD): A study protocol for a randomized controlled trial. Trials 18: 145

42. Ceylan MF, Uneri OS, Guney E, Ergin M, Alisik M, et al. (2014) Increased levels of serum neopterin in attention deficit/hyperactivity disorder (ADHD). J Neuroimmunol 15: 111-114.

43. Ceylan MF, Sener S, Bayraktar AC, Kavutcu M (2012) Changes in oxidative stress and cellular immunity serum markers in attention-deficit/hyperactivity disorder. Psychiatry Clin Neurosci 66: 220-226.

44. Persson T, Popescu BO, Cedazo-Minguez A (2014) Oxidative stress in Alzheimer's disease: why did antioxidant therapy fail. Oxid Med Cell Longev 2014: 427318

45. Pisoschi AM, Pop A (2015) The role of antioxidants in the chemistry of oxidative stress: A review. Eur J Med Chem 97: 55-74.

46. Bulut M, Selek S, Gergerlioglu H, Savas HA, Yilmaz HR, et al. (2007) Malondialdehyde levels in adult attention-deficit hyperactivity disorder. Psychiatr Neurosci 32: 435-438.

47. Selek S, Bulut M, Ocak AR, Kalenderoğlu A, Savaş HA et al. (2012) Evaluation of total oxidative status in adult attention deficit hyperactivity disorder and its diagnostic implications. J Psychiatr Res 46: 451-455.

48. Bulut M, Selek S, Bez Y, Cemal Kaya M, Gunes M, et al. (2013) Lipid peroxidation markers in adult attention deficit hyperactivity disorder: new findings for oxidative stress. Psychiatry Res 209: 638-642.

49. Bonvicini C, Faraone S, Scassellati C (2016). Attention-deficit hyperactivity disorder in adults: a systematic review and meta-analysis of genetic pharmacogenetic and biochemical studies. Mol Psychiatry 21: 872-884.
50. Karababa IF, Savas SN, Selek S, Cicek E, Cicek El, et al. (2017) Homocysteine levels and oxidative stress parameters in patients with adult ADHD. J Atten Disord 21: 487-493.

51. Spahis S, Vanasse M, Belanger SA, Ghadirian P, Grenier E, et al. (2008) Lipid profile, fatty acid composition and pro- and anti-oxidant status in pediatric patients with attention-deficit/hyperactivity disorder. Prostaglandines, Leukotrienes and Essential Fatty Acids 79: 47-53.

52. Oztop D, Altun H, Baskol G, Ozsoy S (2012) Oxidative stress in children with attention deficit hyperactivity disorder. Clin Biochem 45: 745-748.

53. Faraone SV, Bonvicini C, Scassellati C (2014) Biomarkers in the diagnosis of ADHD-Promising directions. Curr Psychiatry Rep 16: 497

54. Rahman K (2007) Studies on free radicals, antioxidants, and cofactors. Clin Interv Aging 2: 219-236.

55. Popa-Wagner A, Mitran S, Sivanesan S, Chang E, Buga AM (2013) ROS and brain diseases: the good, the bad, and the ugly. Oxid Med Cell Longev 2013 963520 .

56. Maes M, Galecki P, Chang YS, Berk M (2011) A review on the oxidative and nitrosative stress (O\&NS) pathways in major depression and their possible contribution to the (neuro)degenerative processes in that illness. Prog Neuropsychopharmacol Biol Psychiatry 35: 676-692.

57. Erel O (2005) A new automated colorimetric method for measuring total oxidant status. Clin Biochem 38: 1103-1111.

58. Jun S, Chun OK, Joung H (2017). Estimation of dietary total antioxidant capacity of Korean adults. Eur J Nutr 56.

59. Wesolowski P, Zawada K, Wojtowicz A, Strużycka I, Kamiński T, et al. (2016) Assessment of salivary total antioxidant capacity in patients with primary untreated head and neck squamous cell carcinoma with ORAC. J Oral Pathol Med 45: 753-757.

60. Celik VK, Ersan E, Ersan S, Bakır S, Dogan O (2013) Plasma catalase glutathione-S-transferase and total antioxidant activity levels of children with attention deficit and hyperactivity disorder. Adv Bioscience Biotechnol 4: $183-187$

61. Selek S, Savas HA, Gergerlioglu HS, Bulut M, Yilmaz HR (2008) Oxidative imbalance in adult attention deficit/hyperactivity disorder. Biol Psychol 79: 256-259.

62. Ceylan MF, Sener S, Bayraktar AC, Kavutcu M (2010) Oxidative imbalance in child and adolescent patients with attention-deficit/hyperactivity disorder. Prog Neuropsychopharmacol Biol Psychiatry 34: 1491-1494.

63. Varol Tas F, Guvenir T, Tas G, Cakaloz B, Ormen M (2006) Nitric oxide levels in disruptive behavioral disorder. Neuropsychobiology 53: 176-180.

64. Ozgur G, Aksu H, Yilmaz M, Karakoç Demirkaya S (2017) The probable role of adrenomedullin and nitric acid in childhood attention deficit hyperactivity disorder. Nord J Psychiatry 71: 521-524.

65. Schoonees A, Visser J, Musekiwa A, Volmink J (2012) Pycnogenol® for the treatment of chronic disorders. Cochrane Database Syst Rev 2012: CD008294.

66. Dvorakova M, Jezova D, Blazicek P, Trebatická J, Skodácek I, et al. (2007) Urinary catecholamines in children with attention deficit hyperactivity disorder (ADHD): modulation by a polyphenolic extract from pine bark (pycnogenol) Nutr Neurosci 10: 151-157.

67. Cremers CM, Jakob U (2013) Oxidant sensing by reversible disulphide bond formation. J Biol Chem 288: 26489-26496.

68. Jones DP, Liang Y (2009) Measuring the poise of thiol/disulphide couples in vivo. Free Radic Biol Med 47: 1329-1338.

69. Avcil S, Uysal P, Avcil M, Alışık M, Biçer C (2017) Dynamic thiol/disulphide homeostasis in children with attention deficit hyperactivity disorder and its relation with disease subtypes. Compr Psychiatry 73: 53-60.

70. Archana E, Pai P, Prabhu BK, Shenoy RP, Prabhu K, et al. (2012) Altered biochemical parameters in saliva of pediatric attention deficit hyperactivity disorder. Neurochem Res 37: 330-334.

71. Guney E, Cetin FH, Alisik M, Tunca H, Tas Torun Y, et al. (2015) Attention deficit hyperactivity disorder and oxidative stress: a short term follow up study. Psychiatry Res 229: 310-317.

72. Joshi K, Lad S, Kale M, Patwardhan B, Mahadik SP, et al. (2006) 
Citation: Annelies V, Harry R, Ines W, Annelies B, Tess DB, et al. (2018) Evaluation of Biomarkers of Oxidative Stress in Attention-Deficit/Hyperactivity Disorder (ADHD). J Mol Biomark Diagn 9: 390. doi: 10.4172/2155-9929.1000390

Supplementation with flax oil and vitamin $\mathrm{C}$ improves the outcome of attention deficit hyperactivity disorder (ADHD). Prostaglandins Leukotr Essent Fatty Acids 74: 17-21.

73. Patrick RP, Ames BN (2015) Vitamin D and the omega-3 fatty acids contro serotonin synthesis and action, part 2: relevance of aDHD, bipolar disorder, schizophrenia, and impulsive behavior. FASEB J 29: 2207-2222.

74. Mossin MH, Aaby JB, Dalgard C, Lykkedegn S, Christesen HT, et al. (2017) Inverse associations between cord vitamin $\mathrm{D}$ and attention deficit hyperactivity disorder symptoms: A child cohort study. Aust NZ J Psychiatry 51: 703-710.

75. Morales E, Julvez J, Torrent M, Ballester F, Rodríguez-Bernal CL, et al. (2015) Vitamin D in pregnancy and attention deficit hyperactivity disorder-like symptoms in childhood. Epidemiology 26: 458-465.

76. Strom M, Halldorsson TI, Hansen S, Granström C, Maslova E, et al. (2014) Vitamin D measured in maternal serum and offspring neurodevelopmental outcomes: A prospective study with long-term follow-up. Ann Nutr Metab 64 254-261.

77. Gustafsson P, Rylander L, Lindh CH, Jönssonet AG, Ode A, et al. (2015) Vitamin D Status at Birth and Future Risk of Attention Deficit/Hyperactivity Disorder (ADHD). PLoS 10: e0140164.

78. Bener A, Kamal M (2013) Predict attention deficit hyperactivity disorder? Evidence-based medicine. Glob J Health Sci 6: 47-57.

79. Bener A, Kamal M, Bener H, Bhugra D (2014) Higher prevalence of iron deficiency as strong predictor of attention deficit hyperactivity disorder in children. Ann Med Health Sci Res 4: S291-S297.

80. Villagomez A, Ramtekkar U (2014) Iron, magnesium, vitamin D, and zinc deficiencies in children presenting with symptoms of attention-deficit/ hyperactivity disorder. Children 1: 261-279.

81. Goksugur SB, Tufan AE, Semiz M, Gunes C, Bekdas M, et al. (2014) Vitamin $\mathrm{D}$ status in children with attention-deficit-hyperactivity disorder. Pediatr Int 56 : 515-519.

82. Kamal M, Bener A, Ehlayel MS (2014) Is high prevalence of vitamin D deficiency a correlate for attention deficit hyperactivity disorder? Atten Defic Hyperact Disord 6: 73-78.

83. Sharif MR, Madani M, Tabatabaei F, Tabatabaee Z (2015) The relationship between serum vitamin $\mathrm{D}$ level and attention deficit hyperactivity disorder. Iran J Child Neurol 9: 48-53

84. Bala KA, Dogan M, Kaba S, Mutluer T, Aslan O, et al. (2016) Hormone disorder and vitamin deficiency in attention deficit hyperactivity disorder (ADHD) and autism spectrum disorders (ASDs). J Pediatr Endocrinol Metab 29: 1077-1082.

85. Avcil S, Uysal P, Yilmaz M, Erge D, Demirkaya SK, et al. (2017) Vitamin D deficiency and a blunted parathyroid hormone response in children with attention-deficit/hyperactivity disorder. Clin Lab 63: 435-443.

86. Meyer T, Becker A, Sundermann J, Rothenberger A, Herrmann-Lingen C (2017) Attention deficit-hyperactivity disorder is associated with reduced blood pressure and serum vitamin D levels: Results from the nationwide German Health Interview and Examination Survey for Children and Adolescents (KiGGS). Eur Child Adolesc Psychiatry 26: 165-175.

87. Garipardic M, Dogan M, Bala KA, Mutluer T, Kaba S, et al. (2017) Association of attention deficit hyperactivity disorder and autism spectrum disorders with mean platelet volume and vitamin D. Med Sci Monit 23: 1378-1384.

88. Shang-Guan LL, Zhao YR (2015) Serum levels of 25-OHvitamin D in children with attention deficit hyperactivity disorder (Abstract in English). Zhonggua Dan Dai Er Ke Za Zhi 17: 837-840.

89. Mohammadpour N, Jazayeri S, Tehrani-Doost M, Djalali M, Hosseini M et al. (2016) Effect of vitamin D supplementation as adjunctive therapy to methylphenidate on ADHD symptoms: A randomized, double blind, placebocontrolled trial. Nutr Neurosci 21: 202-209.

90. Zaidi SKR, Banu N (2004) Antioxidant potential of vitamins A, E and C in modulating oxidative stress in rat brain. Clin Chim Actoa 340: 229-233.

91. Lahat E, Heyman E, Livne A, Goldman M, Berkovitch M, et al. (2011) Iron deficiency in children with attention deficit hyperactivity disorder. Isr Med Assoc J 13: 530-533

92. D'Amato TJ (2005) Is iron deficiency causative of attention-deficit/hyperactivity disorder? Arch Pediatr Adolesc Med 159: 787-788.
93. Picchietti $D$ (2007) Is iron deficiency an underlying cause of pediatric restless legs syndrome and of attention-deficit/hyperactivity disorder? Sleep Medicine 8: 693-694.

94. Parisi P, Villa MP, Donfrancesco R, Miano S, Paolino MC, et al. (2012) Could treatment or iron deficiency both improve $A D H D$ and reduce cardiovascular risk during treatment with ADHD drugs? Med Hypotheses 79: 246-249.

95. Calarge C, Farmer C, Di-Silvestro R, Arnold LE (2010) Serum ferritin and amphetamine response in youth with attention-deficit/hyperactivity disorder. J Child Adolesc Psychopharmacol 20: 495-502.

96. Cortese S, Azoulay R, Castellanos FX, Chalard F, Lecendreux M, et al. (2012) Brain iron levels in attention-deficit/hyperactivity disorder: a pilot MRI study. World J Biol Psychiatr 13: 223-231.

97. Kwon HJ, Lim MH, Ha M, Kim EJ, Yoo SJ, et al. (2011) Transferrin in Korean children with attention deficit hyperactivity disorder. Psychiatry Investig 8 : 366-371.

98. Yang R, Zhang S, Li R, Zhao Z (2012) Were low transferrin levels associated with ADHD symptoms? Psychiatry Investig 9: 425-426.

99. Antalis CJ, Stevens LJ, Campbell M, Pazdro R, Ericson K, et al. (2006) Omega-3 fatty acid status in attention-deficit/hyperactivity disorder. Prostaglandins, Leukotrienes and Essential Fatty Acids 75: 299-308.

100.Sever Y, Ashkenazi A, Tyano S, Weizman A (1997) Iron treatment in children with attention deficit hyperactivity disorder. A preliminary report. Neuropsychobiology 35: 178-180.

101. Konofal E, Lecendreux M, Arnulf I, Mouren MC (2004) Iron deficiency in children with attention-deficit/hyperactivity disorder. Arch Pediatr Adolesc Med 158: $1113-1115$.

102. Konofal E, Lecendreux M, Deron J, Marchand M, Cortese S, et al. (2008) Effects of iron supplementation on attention deficit hyperactivity disorder in children. Pediatr Neurol 38: 20-26.

103. Hariri M, Azadbakht L (2015) Magnesium, iron and zinc supplementation fo the treatment of attention deficit hyperactivity disorder: A systematic review on the recent literature. Int J Prev Med 6: 83

104.Dodig-Curkovic K, Dovhani J, Curkovic M, Dodig-Radić J, Degmecić D (2009) The role of zinc in the treatment of hyperactivity disorder in children (Abstract in English). Acta Med Croatica 63: 307-313.

105. Lepping P, Huber M (2010) Role of zinc in the pathogenesis of attention-deficit hyperactivity disorder: implications for research and treatment. CNS Drugs 24: 721-728.

106. Arnold LE, DiSilvestro RA (2005) Zinc in attention-deficit/hyperactivity disorder J Child Adolesc Psychopharmacol 15: 619-627.

107. Kozielec T, Starobrat-Hermelin B, Kotkowiak L (1994) Deficiency of certain trace elements in children with hyperactivity. (Abstract in English). Psychiatr Pol 28: 345-353.

108. Toren P, Eldar S, Sela B-A, Wolmer L, Weitz R, et al. (1996) Zinc deficiency in attention-deficit hyperactivity disorder. Biol Psychiatry 40: 1308-1310.

109. Bekaroglu M, Aslan Y, Gedik Y, Değer O, Mocan H, et al. (1996) Relationships between serum free fatty acids and zinc, and attention deficit hyperactivity disorder: A research note. J Child Psychol Psychiatry 37: 225-227.

110. Yorbik O, Ozdag MF, Olgun A, Senol MG, Bek S, et al. (2008) Potential effects of zinc on information processing in boys with attention deficit hyperactivity disorder. Prog Neuropsychopharmacol Biol Psychiatry 32: 662-667.

111. Oner O, Oner P, Bozkurt OH, Odabas E, Keser N, et al. (2010) Effects of zinc and ferritin levels on parent and teacher reported symptom scores in attention deficit hyperactivity disorder. Child Psychiatry Hum Dev 41: 441-447.

112. Mahmoud MM, El-Mazary AA, Maher RM, Saber MM (2011) Zinc, ferritin magnesium and copper in a group of Egyptian children with attention deficit hyperactivity disorder. Ital J Pediatr 37: 60

113. Zhou F, Wu F, Zou S, Chen Y, Feng C, et al. (2016) Dietary, nutrient patterns and blood essential elements in Chinese children with ADHD. Nutrients 8: E352.

114. Viktorinova A, Ursinyova M, Trebaticka J, Uhnakova I, Durackova Z, et al. (2016) Changed plasma levels of zinc and copper to zinc ratio and their possible associations with parent- and teacher-rated symptoms in children with attention-deficit hyperactivity disorder. Biol Trace Elem Res 169: 1-7. 
Citation: Annelies V, Harry R, Ines W, Annelies B, Tess DB, et al. (2018) Evaluation of Biomarkers of Oxidative Stress in Attention-Deficit/Hyperactivity Disorder (ADHD). J Mol Biomark Diagn 9: 390. doi: 10.4172/2155-9929.1000390

Page 9 of 10

115. Tippairote T, Temvirianukul P, Benjapong W, Trachootham D (2017) Hair zinc and severity of symptoms are increased with attention deficit and hyperactivity disorder: A hair multi-element profile study. Biol Trace Elem Res 179: 185-194.

116. Arnold LE, Bozzolo H, Hollway J, Cook A, Di-Silvestro RA, et al. (2005) Serum zinc correlates with parent- and teacher-rated inattention in children with attention-deficit/hyperactivity disorder. J Child Adolesc Psychopharmacol 15 628-636.

117. Arnold LE, Hurt E, Lofthouse N (2013) Attention-deficit/hyperactivity disorder: dietary and nutritional treatments. Child Adolesc Psychiatr Clin N Amer 22 381-402.

118. Sun GX, Wang BH, Zhang YF (2015) Relationship between serum zinc levels and attention deficit hyperactivity disorder in children. (Abstract in English). Zhonggua Dang Dai Er Ke Za Zjo 17: 980-983.

119. Akhondzadeh S, Mohammadi MR, Khademi M (2004) Zinc sulphate as an adjunct to methylphenidate for the treatment of attention deficit hyperactivity disorder in children: A double blind and randomized trial (ISRCTN64132371). BMC Psychiatry 4: 9.

120. Huss M, Völp A, Stauss-Grabo M (2010) Supplementation of polyunsaturated fatty acids, magnesium and zinc in children seeking medical advice for attention-deficit/hyperactivity problems-an observational cohort study. Lipids Health Dis 9: 105

121. Zamora J, Velasquez A, Troncoso L, Barra P, Guajardo K, et al. (2011) Zinc in the therapy of the attention-deficit/hyperactivity disorder in children. A preliminary randomized controlled trial. (Abstract in English). Arch Latinoam Nutr 61: 2422-2246.

122. Arnold LE, Di-Silvestro RA, Bozzolo D, Bozzolo H, Crowl L, et al. (2011) Zinc for attention-deficit/hyperactivity disorder: placebo-controlled doubleblind pilot trial alone and combined with amphetamine. J Child Adolesc Psychopharmacol 21: 1-19.

123. Ghanizadeh A, Berk M (2013) Zinc for treating of children and adolescents with attention-deficit hyperactivity disorder: A systematic review of randomized controlled clinical trials. Eur J Clin Nutr 67: 122-124.

124. Salehi B, Mohammadbeigi A, Sheykholeslam H, Moshiri E, Dorreh F (2016) Omega-3 and zinc supplementation as complementary therapies in children with attention-deficit/hyperactivity disorder. J Res Pharm Pract 5: 22-26.

125. Glasdam SM, Glasdam S, Peters GH (2016) The importance of magnesium in the human body: a systematic literature review. Adv Clin Chem 73: 163-193.

126. Irmisch G, Thome J, Reis O, Hässler F, Weirich S (2011). Modified magnesium and lipoproteins in children with attention deficit hyperactivity disorder (ADHD). World J Biol Psychiatry 12: S63-S65.

127. Kozielec T, Starobrat-Hermelin B (1997) Assessment of magnesium levels in children with attention deficit hyperactivity disorder (ADHD). Magnes Res 10 143-148.

128.Zachara BA (2015) Selenium and selenium-dependent antioxidants in chronic liver disease. Adv Clin Chem 68: 131-151.

129.Dura Trave T, Dieze Bayona V, Yoldi Petri ME, Albesa AS (2014) Dietary patterns in patients with attention deficit hyperactivity disorder. Ann Pediatr (Barc) 80: 206-213.

130. Ode A, Rylander L, Gustafsson P, Lundh T, Källén K, et al. (2015) Manganese and selenium concentration in umbilical cord serum and attention deficit hyperactivity disorder in childhood. Environ Res 137: 373-381.

131. De Oliveira EP, Burini RC (2012) High plasma uric acid concentration: causes and consequences. Diabetol Metab Syndr 4: 12

132. Ohrui T, Yashuda M, Matsui H, Matsui T, Sasaki H (2003) Transient relie of asthma symptoms during jaundice: A possible beneficial role of bilirubin Tokohu J Exp Med 199: 193-196

133. Bulmer AC, Ried K, Blanchfield KH, Wagner KH (2008) The anti-mutagenic properties of bile pigments. Mutat Res 658: $28-41$.

134. Wusthoff CJ, Loe IM (2015) Impact of bilirubin-induced neurologic dysfunction on neurodevelopmental outcomes. Semin Fetal Neonatal Med 20: 52-57.

135. Wei CC, Chang CH, Lin CL, Chang SN, Li TC, et al. (2015) Neonatal jaundice and increased risk of attention-deficit hyperactivity disorder: a populationbased cohort study. J Child Psychol Psyciatr 56: 460-467.

136. Hokkanen L, Launes J, Michelsson K (2014) Adult neurobehavioral outcome of hyperbilirubinemia in full term neonates - A 30 year prospective follow-up study. Peer J 2: e294.

137. Kuzniewicz M, Escobar, Newman TB (2009) No association between hyperbilirubinemia and attention-deficit disorder. Pediatrics 123: e367-368.

138. Jangaard KA, Fell DB, Dodds L, Allen AC (2008) Outcomes in a population of healthy term and near-term infants with serum bilirubin levels of $\geq 325 \mu \mathrm{mol} / \mathrm{L}$ $(\geq 19 \mathrm{mg} / \mathrm{dL}$ ) who were born in Nova Scotia, Canada, between 1994 and 2000 . Pediatrics 122: 119-124.

139. Mackness B, Durrington PN, Mackness MI (1998) Human serum paraoxonase. Gen Pharmacol 31: 329-336.

140. Sezen H, Kandemir H, Savik E, Basmacı Kandemir S, Kilicaslan F, et al. (2016) Increased oxidative stress in children with attention deficit hyperactivity disorder. Redox Rep 21: 248-253.

141. Adham EK, Hassan Al, El-Mahdy AA (2011) Nutritional and metabolic disturbances in attention deficit hyperactivity disease. Res J Med Med Sci 6: 10-16.

142. Russo AJ (2010) Decreased serum Cu/Zn SOD associated with high copper in children with attention deficit hyperactivity disorder (ADHD). J Cent Nerv Syst Dis 2: 9-14.

143. Hariri M, Djazayery A, Djalali M, Saedisomeolia A, Rahimi A, et al. (2012) Effect of $n-3$ supplementation on hyperactivity, oxidative stress and inflammatory mediators in children with attention-deficit-hyperactivity disorder. Malay J Nutr 18: 329-335.

144. Lee JY, Hwang IW, Lim MH, Kwon HJ, Jin HJ (2016) Association of glutathione S-transferases M1, T1 an P1 gene polymorphisms with attention deficit and hyperactivity disorder in Korean children. Gene 586: 228-233.

145. Ghanizadeh A, Namazi MR, Davami MH (2010) G6PD deficiency as a predisposing factor for attention deficit/hyperactivity disorder: a hypothesis. Arch Med Res 41: 391.

146. Ruchi K, Kumar A, Sunil G, Bashir A, Prabhat S (2011) Antioxidant activity in children with ADHD - a comparison in untreated and treated subjects with normal children. Int Med J Malaysia 10: 31-35.

147.Sung CC, Hsu YC, Chen CC, Lin YF, Wu CC (2013) Oxidative stress and nucleic acid oxidation in patients with chronic kidney disease. Oxid Med Cell Longev 2013: 301982.

148. Uchida K, Kanematsu M, Sakai K, Matsuda T, Hattori N, et al. (1998) Proteinbound acrolein: potential markers of oxidative stress. Proceedings of the National Academy of Sciences USA 95: 4882-4887

149. Uchida K (1999) Current status of acrolein as a lipid peroxidation product. Trends in Cardiovasc Med 9: 109-113.

150. Kawatani M, Tsukahara H, Mayumi M (2011) Evaluation of oxidative stress status in children with pervasive developmental disorder and attention deficit hyperactivity disorder using urinary-specific biomarkers. Redox Rep 16: 45-46.

151. Ross M, McKenzie I, Glen I, Bennett CP (2003) Increased levels of ethane, a non-invasive marker of $n-3$ fatty acid oxidation, in breath of children with attention deficit hyperactivity disorder. Nutr Neurosci 6: 277-281.

152. Andreazza AC, Kapczinski F, Kauer-Sant Anna M, Walz JC, Bond DJ, et al. (2009) 3-Nitrotyrosine and glutathione antioxidant system in patients in the early and late stages of bipolar disorder. J Psychiatr Neurosci 34: 263-271.

153. Hermans N, Cos P, Maes L, De Bruyne T, Vanden Berghe D, et al. (2007) Challenges and pitfalls in antioxidant research. Current Med Chem 14 417-430.

154.Wasowics W, Neve J, Peretz A (1993) Optimized steps in fluorometric determination of thiobarbituric acid reactive substances in serum: Importance of extraction $\mathrm{pH}$ and influence of sample preservation and storage. Clin Chem 39: $2522-2526$

155. Calyniuk B, Grochowska-Niedworok E, Walkiewicz K, Kawecka S, Popiołek E, et al. (2016) Malondialdehyde (MDA)-product of lipid peroxidation as marke of homeostasis disorders and aging. Ann Acad Med Silesiensis 70: 224-226.

156. Dalle-Donne I, Rossi R, Colombo R, Giustarini D, Milzani A (2006) Biomarkers of oxidative damage in human disease. Clin Chem 52: 601-623.

157. Schaur RJ, Siems W, Bresgen N, Eckl PM (2015) 4-Hydroxy-nonenal-A bioactive lipid peroxidation product. Biomolecules 5: 2247-2337. 
Citation: Annelies V, Harry R, Ines W, Annelies B, Tess DB, et al. (2018) Evaluation of Biomarkers of Oxidative Stress in Attention-Deficit/Hyperactivity Disorder (ADHD). J Mol Biomark Diagn 9: 390. doi: 10.4172/2155-9929.1000390

158. Roy A, Queirolo E, Peregalli F, Mañay N, Martínez G, et al. (2015) Association of blood levels with urinary $\mathrm{F}_{2}$-8a-isoprostane and 8-hydroxy 2-deoxyguonosine concentrations in first-grade Uruguayan children. Env Res 140 127-135.

159. Tsukahara H, Jiang MZ, Ohta N, Sato S, Tamura S, et al. (2004) Oxidative stress in neonates: evaluation using specific biomarkers. Life Sci 75: 933-938.

160. Ross BM, Glen I (2014) Breath ethane concentrations in healthy volunteers correlate with a systemic marker of lipid peroxidation but not with omega-3 fatty acid availability. Metabolites 4: 572-579.

161. Erel O (2004)A novel automated method to measure total antioxidant response against potent free radical reactions. Clin Biochem 37: 112-119.

162. Selek S, Ceylan MF (2015) A relationship between oxidative stress and attention deficit hyperactivity disorder. In: "Studies on Psychiatric Disorders". Dietrich-Muszalska A, Chauhan V, Grignon S, (Eds), Humana Press, New York, NY, USA.

163. Abu-Khadra MK, Amin OP, Shaker OG, Rabah TM (2013) Parent-reported sleep problems, symptom ratings, and serum ferritin levels in children with attention-deficit/hyperactivity disorder: A case control study. BMC Pediatr 13: 217.

164. Bilici M, Yildirim F, Kandil S, Bekaroğlu M, Yildirmiş S, et al. (2004) Doubleblind, placebo-controlled study of zinc sulfate in the treatment of attention deficit hyperactivity disorder. Prog Neuropsychopharmacol Biol Psychiatry 28 : 181-190.

165. Cortese S, Angriman M (2014) Attention-deficit/hyperactivity disorder, iron deficiency, and obesity: is there a link? Postgrad Med 126: 155-170.

166. Cortese S, Konofal E, Bernardina BD, Mouren MC, Lecendreux M (2009) Sleep disturbances and serum ferritin levels in children with attention-deficit/ hyperactivity disorder. Eur Child Adolesc Psychiatry 18: 393-399.

167. Cortese S, Angriman M, Lecendreux M, Konofal E (2012) Iron and attentiondeficit/hyperactivity disorder: what is the empirical evidence so far? A systematic review of the literature. Expert Rev Neurother 12: 1227-1240.

168. Donfrancesco R, Parisi P, Vanacore N, Martines F, Sargentini V, et al. (2013) Iron and ADHD: time to move beyond serum ferritin levels. J Atten Disord 17: 347-357.

169. Juneja M, Jain R, Singh V, Mallika V (2010) Iron deficiencey in Indian children with attention deficit hyperactivity disorder. Indian Pediatr 47: 955-958.

170. Konofal E, Cortese S, Lecendreux M, Arnulf I, Mouren MC (2005) Effectiveness of iron supplementation in a young child with attention-deficit/hyperactivity disorder. Pediatr 116: e732-734.

171. Konofal E, Cortese S, Marchand M, Mouren MC, Arnulf I, et al. (2007) Impact of restless legs syndrome and iron deficiency on attention-deficit/hyperactivity disorder in children. Sleep Med 8: 711-715.
172. Kul M, Unal F, Kandemir H, Sarkarati B, Kilinc K, et al. (2015) Evaluation of oxidative metabolism in child and adolescent patients with attention deficit hyperactivity disorder. Psychiatr Investig 12: 361-366.

173. Lopresti AL (2015) Oxidative and nitrosative stress in ADHD: possible causes and the potential of antioxidant-targeted therapies. Atten Def Hyp Disord 7 237-247.

174. Menegassi M, Mello ED, Guimaraes LR, Matte BC, Driemeier F, et al. (2010) Food intake and serum levels of iron in children and adolescents with attentiondeficit/hyperactivity disorder. Rev Bras Psiquiatr 32: 132-138.

175. Millichap JG, Yee MM, Davidson SI (2006) Serum ferritin in children with attention-deficit hyperactivity disorder. Pediatr Neurol 34: 200-203.

176. Oner P, Dirik EB, Taner Y, Caykoylu A, Anlar O (2007) Association between low serum ferritin and restless legs syndrome in patients with attention deficit hyperactivity disorder. Tohoku J Exp Med 213: 269-276.

177. Oner O, Alkar OY, Oner P (2008) Relation of ferritin levels with symptom ratings and cognitive performance in children with attention deficit-hyperactivity disorder. Pediatr Int 50: 40-44

178. Oner P, Oner O (2008) Relationship of ferritin to symptom ratings children with attention deficit hyperactivity disorder: effect of comorbidity. Child Psychiatr Hum Dev 39: 323-330.

179. Oner P, Oner O, Azik FM, Cop E, Munir KM (2012) Ferritin and hyperactivity ratings in attention deficit hyperactivity disorder. Pediatr Int 54: 688-692.

180. Ozten E, Kesebir S, Eryilmaz G, Tarhan N, Karamustafalığlu O (2015) Are uric acid plasma levels different between unipolar depression with and without adult attention deficit hyperactivity disorder? J Affect Disord 15: 114-117.

181. Ozten E, Kesebir S, Eryilmaz G, Tarhan N, Karamustafalığlu O (2016) Retraction notice to "Are uric acid plasma levels different between unipolar depression with and without adult attention deficit hyperactivity disorder?" (J. Affect. Disord. 177c, 2015, 114-117). J Affect Disord 206: 350.

182. Percinel I, Yazici KU, Ustundag B (2016). Iron deficiency parameters in children and adolescents with attention-deficit/hyperactivity disorder. Child Psychiatry Hum Dev 47: 259-269.

183. Romanos M, Tiesler CM, Koletzko S, Berdel D, Von Berg A, et al. (2013) No cross-sectional and longitudinal association of ferritin and symptoms of attention-deficit/hyperactivity disorder in a large population-based sample of children: results from the GINIplus and LISAplus studies. Atten Defic Hyperact Disord 5: 313-320.

184. Wang Y, Huang L, Zhang L, Qu Y, Mu D (2017) Iron status in attention-deficit/ hyperactivity disorder: a systematic review and meta-analysis. PLoS One 12: e0169145. 